\title{
Continuous Apomorphine Infusion in Patients with Advanced Parkinson's Disease with Varying Degrees of Functional Impairment
}

\author{
Gabriel Salazar1 $^{*}$, Marta Fragoso' ${ }^{1}$ Jonatan Martí1, Noelia Martín², Rosó Bernal² \\ ${ }^{1}$ Neurology Department, Hospital Consorci Sanitari de Terrassa, Barcelona, Spain \\ ${ }^{2}$ Day-Hospital Nursing Department, Hospital Consorci Sanitari de Terrassa, Barcelona, Spain \\ Email: *gsalaz64@gmail.com
}

How to cite this paper: Salazar, G., Fragoso, M., Martí, J., Martín, N. and Bernal, R. (2016) Continuous Apomorphine Infusion in Patients with Advanced Parkinson's Disease with Varying Degrees of Functional Impairment. Journal of Behavioral and Brain Science, 6, 393-403.

http://dx.doi.org/10.4236/jbbs.2016.610038

Received: August 15, 2016

Accepted: September 13, 2016

Published: September 16, 2016

Copyright (c) 2016 by authors and Scientific Research Publishing Inc. This work is licensed under the Creative Commons Attribution International License (CC BY 4.0).

http://creativecommons.org/licenses/by/4.0/

\begin{abstract}
Introduction: Continuous apomorphine infusion (CAI) is effective in improving complications in advanced Parkinson's disease (APD). The effectiveness and tolerance of CAI in patients with APD with varying degrees of functional impairment was studied. Methods: In this comparative observational study, consecutive APD who started treatment with CAI were included. They were classified into two groups of functional impairment: A) moderate (Schwab and England (S \& E) $=60 \%-80 \%$ and Hoehn and Yahr (H \& Y) = 2 - 3; Group (A), and (B) severe (S \& E < 60; H \& Y > 3; Group B). Clinical follow-up was performed with concomitant medication and CAI adjustment at 3, 6 and 12 months. Clinical evaluation included a dyskinesia diary and AIMS, S \& E, NPI, NMSS and HADS questionnaires. Results: Eighteen patients participated ( $\mathrm{A}=9$ and $\mathrm{B}=9$ ) with EP diagnosed $7(\mathrm{~A})$ and $13(\mathrm{~B})$ years before. Their baseline dose of levodopa was $728 \mathrm{mg}$ (A) and $925 \mathrm{mg}$ (B), which did not change during follow-up. Dopamine agonists were progressively reduced in both groups. Progressive titration of CAI resulted in abandonment of apomorphine bolus administration. Both groups experienced improvements in all variables, higher in group $A$; motor fluctuations $=69 \%(\mathrm{~A}), 53 \%(\mathrm{~B}) ; \mathrm{AIMS}=82 \%(\mathrm{~A}), 71(\mathrm{~B}) ; \mathrm{S} \& \mathrm{E}=32 \%(\mathrm{~A})$, $18 \%(B) ;$ NMS $=62 \%(A), 19 \%(B) ; \mathrm{NPI}=75 \%(\mathrm{~A}), 50 \%(\mathrm{~B}) ;$ HADS $($ anxiety) $=26 \%$ (A), $21 \%(B)$; HADS (depression) $=52 \%(A), 31 \%(B)$. Adverse effects were generally mild and resolved without reducing CAI dose. There were no withdrawals. Conclusions: Patients with APD and moderate functional impairment treated with CAI may obtain greater functional, cognitive and emotional improvement than patients more severely affected.
\end{abstract}




\section{Keywords}

Parkinson’s Disease, Apo Morphine, Continuous Dopaminergic Stimulation

\section{Introduction}

The progression of Parkinson's disease (PD) implies great impairment of unaided mobility, serious motor defects and the risk of falls, together with non-motor symptoms in the form of cognitive and psychotic problems, among other alterations [1]. Advanced PD (APD) is diagnosed when conventional treatment is unable to afford adequate symptoms control, and typically corresponds to stages 4 or 5 on the scale of Hoehn and Yahr. Approximately 50\% of all patients with PD develop complications characteristic of APD 5 years after the initial clinical diagnosis of the disease, including also motor fluctuations, non-motor symptoms and dyskinesias related to the treatment provided [2]. Continuous apomorphine infusion (CAI) has been shown to be effective in improving the motor complications of APD and global functional performance [3]-[5] - this in turn having a positive impact upon patient quality of life [5]. However, information is lacking in the literature on the efficacy of CAI according to the degree of functional impairment of patients with APD. The present comparative observational study was therefore carried out to determine the efficacy of CAI in patients with APD with varying degrees of functional impairment, and their tolerance of such therapy.

\section{Patients and Methods}

This observational study included consecutive patients with PD according to the criteria of the Queen Square Brain Bank for Neurological Disorders (QSBB) [6] attended in the Parkinson and Movement Anomalies Unit of Consorci Sanitari de Terrassa (Barce-

lona, Spain), and in advanced stages of the disease as evidenced from the case history and neurological evaluation. The included patients presented motor and non-motor fluctuations, with disabling OFF periods, i.e., good candidates for some of the treatments approved for APD. A number of subjects were not candidates for deep brain stimulation due to age considerations or cognitive impairment. The start of subcutaneous apomorphine administered via a continuous perfusion pump (CPP) was proposed, following the indications approved in the Summary of Product Characteristics [7]. All patients signed the informed consent document for treatment and participation in the study, which was approved by the Clinical Research Ethics Committee of Consorci Sanitari de Terrassa.

\subsection{Assessment of Functional Impairment and Patient Classification}

Patient functional impairment was assessed using the functional scales of Schwab and England ( $\mathrm{S}$ \& E) and of Hoehn and Yahr (H \& Y) [8]. In order to assess the efficacy of 
CAI and tolerance of treatment according to the degree of functional impairment, the participants were divided into two groups: A) patients with APD and moderate functional impairment, defined by an S \& E score of $60 \%-80 \%$ and $\mathrm{H} \& \mathrm{Y}$ stages $2-3$ (Group A); and B) patients with APD and severe functional impairment, defined by an $S \&$ E score of $<60 \%$ and H \& Y stage $>3$ (Group B).

\subsection{Procedure}

At the start of the study, the patients were seen in the Neurology Day Hospital, where a CAI starting test was made and health education instructions were given to the patient relatives or caregivers over 3 - 4 days. Initial apomorphine infusion (Apo morphine 10 $\mathrm{mg} / \mathrm{ml}$, solution for perfusion; Archimedes Pharma Ibérica, S.L., Madrid, Spain) at 5 $\mathrm{mg} / \mathrm{ml}$ dilution was performed at a rate of $0.20 \mathrm{ml} / \mathrm{h}$. The perfusion rate was adjusted according to clinical response, in the form of $0.20 \mathrm{ml} / \mathrm{h}$ increments, until clear improvement was observed in terms of the intended symptoms control, or until side effects appeared. In all patients perfusion during 12 hours a day was recommended, with dose adjustments on occasion of the subsequent follow-up visits. The antiparkinson drugs used by the patients up until that time were maintained after the starting phase, and were gradually adjusted or suspended over the follow-up visits, according to clinical response and the patient evaluation results. These previous treatments included levodopa, dopaminergic agonists (pramipexol and rotigotine) and pen-administered apomorphine (APO-go PEN $10 \mathrm{mg} / \mathrm{ml}$ Britannia Pharmaceuticals Ltd., Newbury, United Kingdom), which the patients used as rescue medication. The patients were evaluated at inclusion (assessment before the start of CAI) and over a one-year follow-up period (after 1, 3, 6 and 12 months).

\subsection{Endpoints}

Validated instruments for patient clinical and functional assessment were used on each visit: 1) patient motor fluctuations diary; 2) AIMS (Abnormal Involuntary Movement Scale) [9]; 3) S \& E functional assessment scale [10]; 4) NPI (Neuropsychiatric Inventory) [10]; 5) NMSS (Non-Motor Symptoms Scale) [11]; and 6) HADS [12] (Hospital Anxiety and Depression Scale).

\subsection{Statistical Analysis}

A first descriptive analysis was made. Continuous variables were reported as the mean and standard deviation, while qualitative variables were reported as frequencies and percentages. Because of the small sample size, use was made of the nonparametric Friedman test, followed by the Wilcox on test with two-by-two comparisons to analyse the evolution of the different study variables at each of the follow-up time points. There was a power calculation for the sample. The percentage changes between the baseline condition and situation after 12 months were compared using the Mann-Whitney U-test. The R statistical package was used, and statistical significance was considered for $\mathrm{p}<0.05$. 


\section{Results}

Nineteen patients with APD participated in the study: 9 with moderate functional impairment (Group A) and 9 with severe functional impairment (Group B). The clinical and demographic data are shown in Table 1. The patients in Group A and Group B had been diagnosed with PD an average of $7.9 \pm 0.8$ and $13.3 \pm 0.7$ years ago, respectively. Before the start of CAI, all the subjects were receiving levodopa, with a dose of $723 \pm 15$ $\mathrm{mg}$ in Group A and $920 \pm 12 \mathrm{mg}$ in Group B. In addition, all subjects in Group A received pramipexol, while in Group B six patients received rotigotine in patch form and three received pramipexol (Table 2). Dopaminergic agonist use was reduced over follow-up and finally suspended after 6 months in all patients in Group A. After this time, only one patient in Group B continued to receive rotigotine, at a dose of $4 \mathrm{mg}$ (far lower than the initial dose) (Table 2). This same patient also received $2.1 \mathrm{mg}$ of pramipexol, which could be suspended three months after starting CAI.

The levodopa doses did not experience relevant changes during the 12 months of the study, though there was a progressive reduction in the number and volume of apomorphine pen injections administered as rescue treatment in both groups. At the end of the study only one patient continued to use the pen injections as a single $6 \mathrm{mg}$ daily bolus dose (Table 2).

The initial mean apomorphine in $5 \mathrm{mg} / \mathrm{ml}$ dilution perfusion rate was $0.4 \pm 0.2 \mathrm{ml} / \mathrm{h}$ and $0.4 \pm 0.2 \mathrm{ml} / \mathrm{h}$ in Group A and Group B, respectively, and to this the patients moreover added 2 - 3 daily bolus doses of $4 \mathrm{mg}$. The perfusion rate was gradually increased in both groups until reaching an average of $1.2 \pm 0.2 \mathrm{ml} / \mathrm{h}$ and $0.9 \pm 0.1$ in Group A and Group B, respectively, at the end of the study. The number of CAI boluses remained stable in both groups at the end of the study (Table 2).

Table 1. Baseline demographic and clinical characteristics of the patients with advanced parkinson's disease according to the degree of functional impairment (group a: moderate; group b: severe). The significant values appear in boldface.

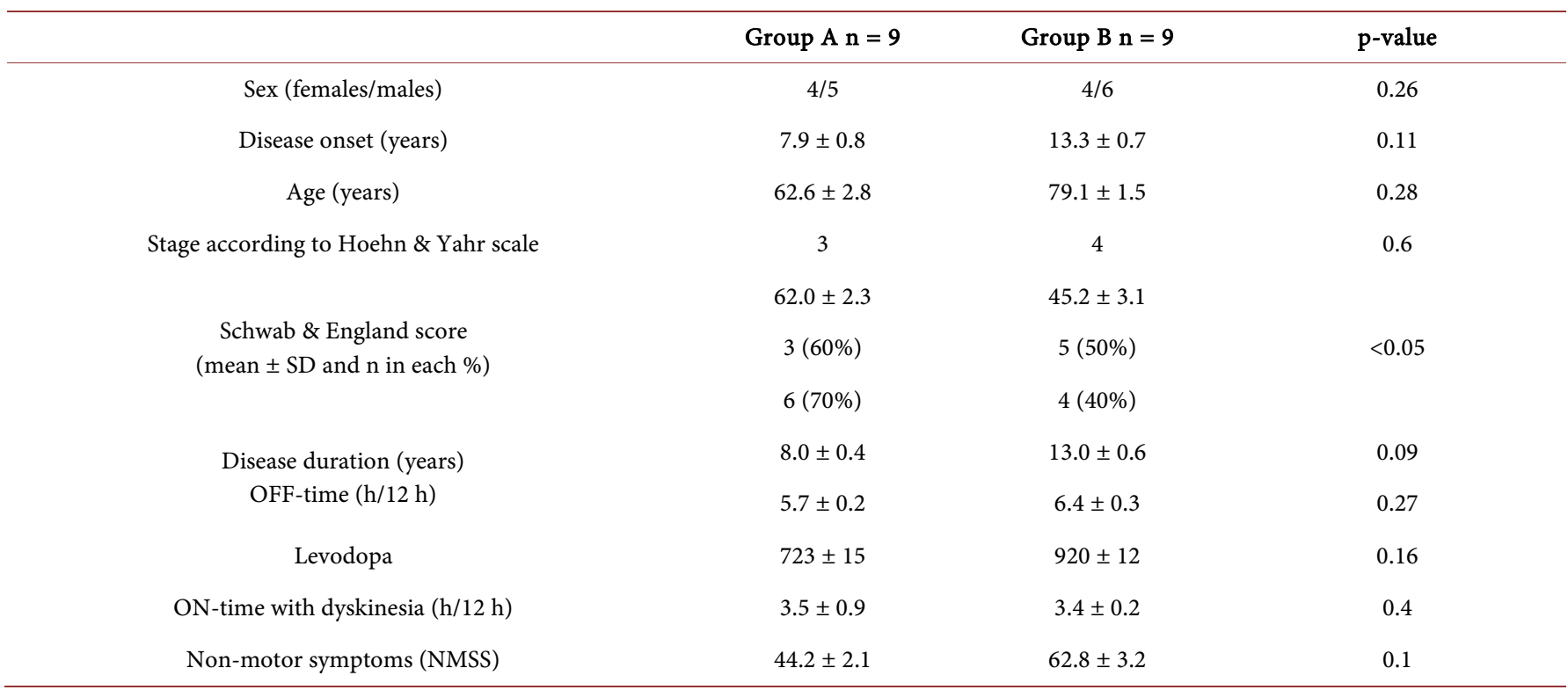


Table 2. Mean total dose of levodopa, dopaminergic agonists and apomorphine infusion in patients with advanced parkinson's disease and moderate (group A) or severe functional impairment (group B).

\begin{tabular}{|c|c|c|c|c|c|}
\hline Group A (n=9) & Start & 3 months & 6 months & 9 months & 12 months \\
\hline Levodopa (mg) & $723 \pm 15$ & $722 \pm 11$ & $722 \pm 6$ & $723 \pm 6$ & $730 \pm 8$ \\
\hline \multicolumn{6}{|c|}{ Dopaminergic agonists } \\
\hline Pramipexol, no. patients (mg) & $9(2.6 \pm 0.2)$ & $3(2.1 \pm 0.2)$ & - & - & - \\
\hline $\mathrm{mg} /$ day & $66 \pm 3$ & $32 \pm 4$ & $18 \pm 2$ & $5 \pm 2$ & - \\
\hline no. boluses & 8 & 2 & 2 & 1 & \\
\hline 12 hours/day & 12 & $11.8 \pm 0.2$ & $11.8 \pm 0.2$ & $11.6 \pm 0.4$ & $11.4 \pm 0.6$ \\
\hline no. boluses (bolus volume) & $2(0.4 \mathrm{ml})$ & $3(0.3 \mathrm{ml})$ & $3(0.3 \mathrm{ml})$ & $2(0.3 \mathrm{ml})$ & $2(0.3 \mathrm{ml})$ \\
\hline Group B $(n=6)$ & Start & 3 months & 6 months & 9 months & 12 months \\
\hline Levodopa (mg) & $920 \pm 12$ & $923 \pm 10$ & $933 \pm 5$ & $910 \pm 20$ & $915 \pm 16$ \\
\hline \multicolumn{6}{|c|}{ Dopaminergic agonists: } \\
\hline \multicolumn{6}{|l|}{ Pen-delivered apomorphine } \\
\hline no. boluses & 5 & 3 & 2 & 1 & 1 \\
\hline \multicolumn{6}{|l|}{ Apomorphine in perfusion } \\
\hline $\mathrm{ml} / \mathrm{h}$ & $0.4 \pm 0.2$ & $0.8 \pm 0.2$ & $0.9 \pm 0.2$ & $0.9 \pm 0.1$ & $0.9 \pm 0.1$ \\
\hline 12 hours/day & 12 & $11.7 \pm 0.2$ & $11.5 \pm 0.1$ & $11.1 \pm 0.2$ & $11.1 \pm 0.2$ \\
\hline no. boluses & 3 & 2 & 2 & 2 & 2 \\
\hline
\end{tabular}

With regard to the clinical variables, the patients in Group A showed a $63.9 \%$ decrease in motor fluctuations on occasion of the final study visit, with an estimated duration of two hours every 12 hours at the end, versus 5.5 hours at baseline (Table 3). Dyskinesia decreased $85.7 \%$ according to the AIMS over the mentioned period of time, and significant improvements were also observed on the S \& E scale (28.6\%), in the non-motor symptoms (NMS, $62.0 \%$ improvement), and in the neuropsychiatric symptoms as scored by the NPI (74.9\% improvement) (Table 3 ).

The patients in Group B likewise experienced improvements in all aspects, though mostly to a comparatively lesser degree (Figure 1). Specifically, the motor fluctuations had decreased $56.4 \%$ after 12 months of follow-up (from $7.0 \pm 0.6 \mathrm{~h} / 12 \mathrm{~h}$ to $3.0 \pm 0.6$ $\mathrm{h} / 12 \mathrm{~h}$ ), the AIMS dyskinesia score improved $74.0 \%$, and the $\mathrm{S} \& \mathrm{E}$ score had improved $16.7 \%$, with a mean impairment of $70 \%$ at the end of the study. On the other hand, the neuropsychiatric symptoms also improved $49.9 \%$ (NPI), and the non-motor symptoms improved 18.8\% (NMSS) (Table 4).

The study of the patient emotional profile based on the HADS showed both groups of subjects to experience significant improvement in relation to anxiety and depression, with $24 \%$ and $22 \%$ improvement on the anxiety subscale in Groups A and B, respectively, and $40 \%$ and $32 \%$ improvement on the depression subscale, respectively.

The analysis of the evolution of the clinical symptoms, comparing the results between visits, revealed significant improvements after 3, 6 and 12 months versus baseline for all the variables and in both groups (Table 5).

On comparing the improvement recorded after 12 months of treatment with CAI 
Table 3. Results of follow-up referred to motor and non-motor symptoms and emotional state of the patients in group a (moderate functional impairment).

\begin{tabular}{ccccccc}
\hline Mean & $\begin{array}{c}\text { Start } \\
\text { (pre-CAI) }\end{array}$ & 3 months & 6 months & $\begin{array}{c}\text { 12 months } \\
\text { Final }\end{array}$ & $\begin{array}{c}\text { \% improvement } \\
\text { start-end }\end{array}$ & p-value \\
\hline MF in 12 h & $5.5 \pm 0.5$ & $1.0 \pm 0.5$ & $0.9 \pm 0.4$ & $2.0 \pm 0.6$ & $63.9 \%$ & $0.001^{*}$ \\
AIMS & $14 \pm 0.6$ & $7 \pm 0.6$ & $4 \pm 1.4$ & $2 \pm 6.3$ & $85.7 \%$ & $<0.001^{*}$ \\
\% in S \& E & $70 \%$ & $90 \%$ & $90 \%$ & $90 \%$ & $28.6 \%$ & $<0.001^{*}$ \\
NPI & $8.0 \pm 0.6$ & $4.2 \pm 0.7$ & $2.0 \pm 0.6$ & $2.0 \pm 0.6$ & $74.9 \%$ & $0.001^{\star}$ \\
NMSS & $42.2 \pm 2.2$ & $22 \pm 2.3$ & $20.7 \pm 4.3$ & $16 \pm 1.4$ & $62.0 \%$ & $0.002^{\star}$ \\
HADS A & $8.0 \pm 0.6$ & $6.0 \pm 0.6$ & $6.0 \pm 0.6$ & $4.0 \pm 0.6$ & $24.1 \%$ & $0.008^{*}$ \\
\multicolumn{1}{c}{ D } & $15 \pm 0.9$ & $13 \pm 0.6$ & $12.8 \pm 1.0$ & $9.2 \pm 1.0$ & $39.9 \%$ & $0.001^{\star}$ \\
\hline
\end{tabular}

CAI, continuous apomorphine infusion; MF, motor fluctuations; S \& E, Schwab and England scale; AIMS, Abnormal Involuntary Movement Scale; NPI, Neuropsychiatric Inventory; NMSS, Non-Motor Symptoms Scale; HADS, Hospital Anxiety (A) and Depression (D) Scale. Analysis made with the Friedman test.

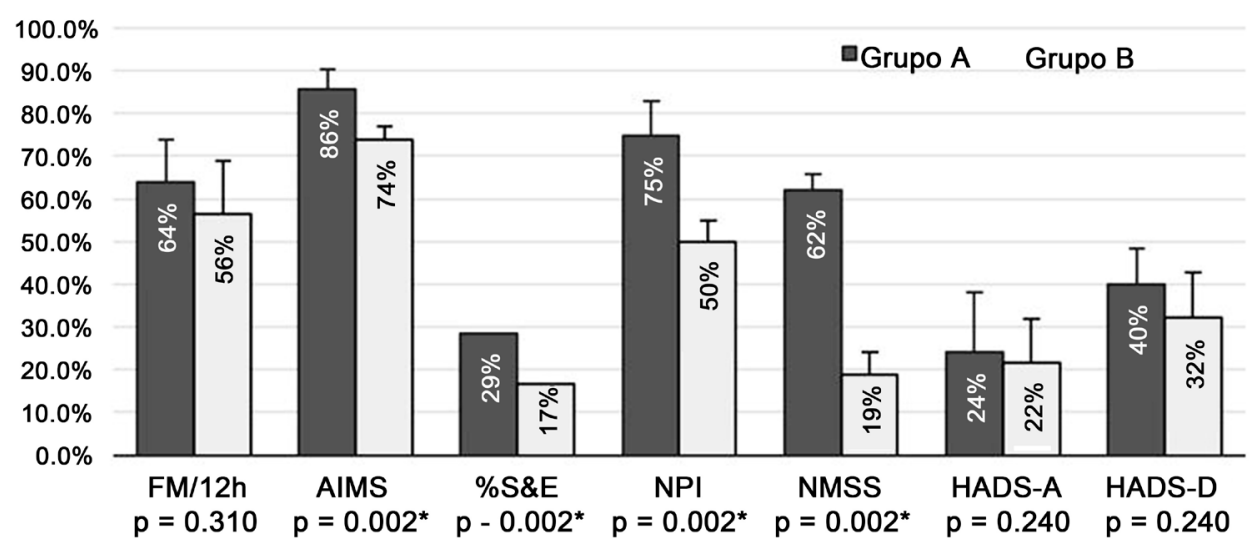

Figure 1. Comparison of percentage improvement of the study endpoints according to the degree of functional impairment (group a: moderate; group b: severe). The patients with moderate functional impairment experienced greater improvement, with statistically significant differences according to S \& E, NPI and NMSS. MF, motor fluctuations; S \& E, schwab and england scale; aims, abnormal involuntary movement scale; npi, neuropsychiatric inventory; NMSS, Non-Motor symptoms scale; HADS, hospital anxiety (A) and depression (D) scale.

between Group A and Group B, the patients with moderate functional impairment were seen to reach higher percentage improvement in all the tests. The difference was statistically significant versus the patients with severe functional impairment in the case of the AIMS, S \& E, NPI and NMSS (Figure 1).

As regards the tolerance of treatment, all the adverse effects described below improved, and none of the patients were lost to follow-up. Four patients in Group A suffered nausea that could be controlled with $10 \mathrm{mg}$ of domperidone every 8 hours, without having to lower the apomorphine dose. Three patients in Group B likewise suffered nausea which domperidone was able to control only partially. Lowering of the CAI dose therefore proved necessary, after which the nausea disappeared. Three patients experienced drowsiness during the first month. Two patients in Group A suffered anxiety, 
Table 4. Results of follow-up referred to motor and non-motor symptoms and emotional state of the patients in group B (severe functional impairment).

\begin{tabular}{|c|c|c|c|c|c|c|}
\hline Mean & $\begin{array}{c}\text { Start } \\
\text { (pre-CAI) }\end{array}$ & 3 months & 6 months & $\begin{array}{l}12 \text { months } \\
\text { Final }\end{array}$ & $\begin{array}{c}\% \text { improvement } \\
\text { start-end }\end{array}$ & p-value ${ }^{*}$ \\
\hline $\mathrm{MF}$ in $12 \mathrm{~h}$ & $7.0 \pm 0.6$ & $4.1 \pm 0.4$ & $3.0 \pm 0.1$ & $3.0 \pm 0.6$ & $56.4 \%$ & $0.001^{*}$ \\
\hline$\%$ in $\mathrm{S} \& \mathrm{E}$ & $60 \%$ & $70 \%$ & $70 \%$ & $70 \%$ & $16.7 \%$ & $<0.001^{\star}$ \\
\hline NPI & $16 \pm 0.6$ & $7.8 \pm 0.8$ & $6.2 \pm 1.0$ & $8 \pm 0.6$ & $49.9 \%$ & $0.001^{*}$ \\
\hline \multirow{2}{*}{ HADS } & $9.0 \pm 0.6$ & $7.0 \pm 1.3$ & $7.0 \pm 0.6$ & $7.0 \pm 0.6$ & $21.7 \%$ & $0.016^{*}$ \\
\hline & $17.3 \pm 2.4$ & $16.2 \pm 8$ & $14.2 \pm 1.2$ & $12.9 \pm 0.5$ & $32.1 \%$ & $0.001^{\star}$ \\
\hline
\end{tabular}

CAI, continuous apomorphine infusion; MF, motor fluctuations; S \& E, Schwab and England scale; AIMS, Abnormal Involuntary Movement Scale; NPI, Neuropsychiatric Inventory; NMSS, Non-Motor Symptoms Scale; HADS, Hospital Anxiety (A) and Depression (D) Scale. Analysis made with the Friedman test.

Table 5. Comparisons of the evolution of clinical outcomes at the different follow-up time points (p-values).

\begin{tabular}{|c|c|c|c|c|c|c|c|c|c|c|c|c|c|c|}
\hline \multirow[b]{2}{*}{ Group } & \multicolumn{2}{|c|}{ MF } & \multicolumn{2}{|c|}{ AIMS } & \multicolumn{2}{|c|}{$\% \mathrm{SE}$} & \multicolumn{2}{|c|}{ NPI } & \multicolumn{2}{|c|}{ NMSS } & \multicolumn{2}{|c|}{ HADS-A } & \multicolumn{2}{|c|}{ HADS-D } \\
\hline & A & B & A & B & A & B & A & B & A & B & A & B & A & B \\
\hline Start/3 months & $0.026^{*}$ & $0.026^{*}$ & $0.024^{\star}$ & $0.026^{\star}$ & $0.014^{\star}$ & $0.014^{\star}$ & $0.026^{*}$ & $0.027^{\star}$ & $0.026^{\star}$ & $0.043^{\star}$ & $0.038^{\star}$ & $0.039^{*}$ & $0.026^{*}$ & 0.115 \\
\hline Start/6 months & $0.026^{*}$ & $0.027^{\star}$ & $0.026^{*}$ & $0.027^{\star}$ & $0.014^{*}$ & $0.014^{*}$ & $0.026^{*}$ & $0.027^{\star}$ & $0.027^{\star}$ & $0.027^{\star}$ & $0.024^{\star}$ & $0.024^{*}$ & $0.027^{\star}$ & $0.027^{\star}$ \\
\hline Start/12 months & $0.024^{*}$ & $0.026^{*}$ & $0.026^{*}$ & $0.027^{\star}$ & $0.014^{*}$ & $0.014^{*}$ & $0.026^{*}$ & $0.026^{*}$ & $0.028^{*}$ & $0.028^{*}$ & $0.034^{*}$ & $0.026^{*}$ & $0.027^{*}$ & $0.027^{*}$ \\
\hline 3 months $/ 12$ months & $0.039^{*}$ & $0.042^{*}$ & $0.024^{*}$ & $0.042^{*}$ & 1 & 1 & $0.026^{*}$ & 0.317 & $0.026^{*}$ & 0.598 & 1 & 0.890 & $0.024^{*}$ & $0.027^{*}$ \\
\hline 6 months $/ 12$ months & $0.026^{*}$ & 1 & $0.034^{\star}$ & $0.026^{\star}$ & 1 & 1 & $0.034^{*}$ & $0.026^{*}$ & $0.046^{\star}$ & 1 & 1 & 1 & $0.026^{*}$ & $0.039^{\star}$ \\
\hline
\end{tabular}

MF, motor fluctuations; S \& E, Schwab and England scale; AIMS, Abnormal Involuntary Movement Scale; NPI, Neuropsychiatric Inventory; NMSS, Non-Motor Symptoms Scale; HADS, Hospital Anxiety (A) and Depression (D) Scale. Analysis made with the Wilcoxon signed-rank test for paired data. The significant values appear in boldface.

which improved on reducing the treatment with pramipexol. Four patients in Group B experienced episodes of euphoria, which were controlled by lowering the CAI dose. None of the patients suffered hallucinations, though two of the subjects in Group B experienced hyper sexuality and jealousy attacks that improved on lowering the treatment dose, without having to resort to neuroleptics. Lastly, four patients developed subcutaneous nodules that caused no discomfort. Skin treatment was required in only two of these cases.

\section{Discussion}

In the past few years, non-controlled trials have demonstrated the efficacy of CAI in improving the motor problems of patients with APD [13]-[15]. These good results have been supported by more recent series that have addressed both motor fluctuations and dyskinesias on one hand and non-motor symptoms and quality of life on the otherwith the demonstration of improvements in the different areas [3]-[5]. However, in view of the current challenge posed by the management of APD and the diversity of the 
patient characteristics (including the definition of APD as such), the criteria used to identify candidates for the different treatment modalities remains the subject of debate [13]-[22]. In this context, the published studies on the usefulness of CAI in APD lack consensus as to when treatment should be started counting from the time of diagnosis or symptoms progression. The patients included in the recent studies present severe functional impairment [3]-[5], and this appears to be associated to a high incidence of side effects that contribute to shorten the duration of treatment (about 26 months on average), and to treatment suspension because of loss of efficacy or side effects [19]. It is not common for these studies to include patients with APD and only moderate functional impairment, and such subjects are moreover few in proportion to the overall study sample. Little published experience on this subpopulation is therefore available.

In the present study, the patients with APD and moderate functional impairment (Group A) experienced greater global improvement than the patients with severe functional impairment (Group B) in the course of the 12 months of follow-up (Figure 1). This more marked improvement among patients with less severe disease was evidenced by the results of the functional scales, motor fluctuations and dyskinesias recorded in the patient diary, non-motor Parkinson symptoms and strictly neuropsychiatric symptoms.

Although our small sample size does not allow the drawing of firm conclusions, this small single-centre series can yield an appraisal based on the individualised analysis of the included patients. At the start of the study we observed that the patients with greater functional impairment not only presented greater alterations in executive aspects but also greater walking instability and global cognitive impairment, resulting in greater overall dependency. These patients showed improvement as evaluated by the AIMS and reductions in motor fluctuation of a magnitude similar to that seen in the Group A patients with moderate impairment (albeit with a significant difference in AIMS score in favour of Group A). However, the magnitude of the benefits in relation to the neuropsychiatric and non-motor symptoms was significantly smaller among the more severely affected individuals than in those with moderate functional impairment. The global deterioration of the patients in Group B very possibly contributed to the fact that the improvement observed after introducing CAI did not result in important functional improvement compared with the less severely affected patients. It has recently been suggested that this treatment should be considered earlier than usual in current practice (i.e., in patients with very advanced disease) [13]-[24]. On one hand, many patients and caregivers consider that apomorphine in a less advanced stage of the disease would have been more beneficial [25]. On the other hand, patients with more advanced Parkinson's disease and of older age appear to experience psychotic symptoms more often [22], and can suffer more adverse effects.

In this study, we did not significantly modify the levodopa doses of the patients in the course of follow-up, though other dopaminergic agonists were successfully withdrawn [20]. The combination of levodopa and CAI has previously been proposed as a good management option [9], though the recommendation is to lower the levels to the minimum needed to control the symptoms [13]-[24]. At the end of follow-up, the pa- 
tients with moderate functional impairment were using higher doses for the control of their symptoms, with a mean infusion rate of $6 \mathrm{mg} / \mathrm{h}$ (11.4 hours/day) and an average of two $0.3 \mathrm{ml}$ bolus doses, while the patients with greater functional impairment were using $4.5 \mathrm{mg} / \mathrm{h}$ ( 11.1 hours/day) and two $0.3 \mathrm{ml}$ bolus doses. The explanation for this is that the patients with greater functional impairment generally did not tolerate higher doses because of adverse effects that were usually mild but which made it necessary to use lower doses. It is very likely that this lower dosage also contributed to the more discrete improvement observed in this group, in concordance with the results of a study in which low-dose apomorphine was associated to a lack of efficacy in application to the motor symptoms [26].

On the other hand, the improvements in all the evaluated aspects were observed from three months after the start of CAI, with a slow but progressive increase in the course of the 12 months of follow-up. This is very possibly attributable to the slow increase in perfusion dose prescribed, which in the clinical context may have contributed to more easily avoid and treat the side effects of apomorphine [13] [27]. In this regard, adverse effects developed indistinctly in both patient groups, and were mild and well tolerated in all cases, in coincidence with the data found in the literature [13] [16] [28].

This study has the limitations inherent to a single-centre observational study with a small sample size, though the results offer initial information on an aspect that would be interesting to explore. Our findings suggest new therapeutic possibilities for patients with APD and moderate functional impairment that fail to improve with conventional treatment, and which are less widely represented in studies on alternative treatments for APD. In our series the patients in Group A (moderate functional impairment) showed greater functional, cognitive and emotional improvement than the patients with more severe functional impairment. Greater global deterioration could reduce the benefits of CAI in APD. These observations indicate that patients with APD amenable to treatment with CAI who do not suffer severe functional and cognitive impairment, and who are not strongly dependent, could derive greater benefit from such treatment. This issue deserves more in-depth investigation in the context of studies involving larger patient samples and longer follow-up, in order to draw firm conclusions.

\section{Acknowledgements}

We thank our colleagues, Dr. Antoni Rey and Dr. Marta Fragoso, for their collaboration in this study.

\section{Funding}

This study has been fully financed by the Joan Costa Roma Foundation. CST. Terrassa (Barcelona), Spain.

\section{References}

[1] Kulisevsky, J., Luquin, M.R., Arbelo, J.M., Burguera, J.A., Carrillo, F., Castro, A., et al. (2013) Advanced Parkinson's Disease: Clinical Characteristics and Treatment. Part I. Neurologia, 28, 503-521. http://dx.doi.org/10.1016/j.nrl.2013.05.001 
[2] Maetzler, W., Liepelt, I. and Berg, D. (2009) Progression of Parkinson's Disease in the Clinical Phase: Potential Markers. The Lancet Neurology, 8, 1158-1171.

http://dx.doi.org/10.1016/S1474-4422(09)70291-1

[3] García Ruiz, P.J., Sesar Ignacio, A., Ares Pensado, B., Castro García, A., Alonso Frech, F., Alvarez López, M., et al. (2008) Efficacy of Long-Term Continuous Subcutaneous Apomorphine Infusion in Advanced Parkinson's Disease with Motor Fluctuations: A Multicenter Study. Movement Disorders, 23, 1130-1136. http://dx.doi.org/10.1002/mds.22063

[4] Katzenschlager, R., Hughes, A., Evans, A., Manson, A.J., Hoffman, M., Swinn, L., et al. (2005) Continuous Subcutaneous Apomorphine Therapy Improves Dyskinesias in Parkinson's Disease: A Prospective Study Using Single-Dose Challenges. Movement Disorders, 20, 151-157. http://dx.doi.org/10.1002/mds.20276

[5] Martínez-Martín, P., Reddy, P., Katzenschlager, R., Antonini, A., Todorova, A., Odin, P., et al. (2015) EuroInf: A Multicenter Comparative Observational Study of Apomorphine and Levodopa Infusion in Parkinson's Disease. Movement Disorders, 30, 510-516. http://dx.doi.org/10.1002/mds.26067

[6] Berardelli, A., Wenning, G.K., Antonini, A., Berg, D., Bloem, B.R., Bonifati, V., et al. (2013) EFNS/MDS-ES/ENS [Corrected] Recommendations for the Diagnosis of Parkinson's Disease. European Journal of Neurology, 20, 16-34. http://dx.doi.org/10.1111/ene.12022

[7] Spanish Agency for Medicines and Health Products (AEMPS). Sheet: Archimedes Apomorphine $10 \mathrm{mg} / \mathrm{ml}$ Solution for Injection/Infusion.

http://www.aemps.gob.es/cima/pdfs/es/ft/72074/P_72074.pdf

[8] Perlmutter, J.S. (2009) Assessment of Parkinson Disease Manifestations. Current Protocols in Neuroscience/Editorial Board.

[9] Guy, W. (1988) ECDEU Assessment Manual for Psychopharmacology, Revised Ed. Washington, DC, US Department of Health, Education, and Welfare, 1976. A Nice Practical Discussion Can Be Found in Munetz MR, Benjamin S. How to Examine Patients Using the Abnormal Involuntary Movement Scale. Hospital and Community Psychiatry, 39, 1172-1177.

[10] Martinez-Martin, P. (1993) Rating Scales in Parkinson’s Disease. In: Jankovic, J. and Tolosa, E., Eds., Parkinson's Disease and Movement Disorders, Williams and Wilkins, Baltimore, 281-292.

[11] Chaudhuri, K.R., Healy, D. and Shapira, A.H.V. (2006) The Non Motor Symptoms of Parkinson's Disease NMS Quest. Diagnosis and Management. The Lancet Neurology, 5, 235-245. http://dx.doi.org/10.1016/S1474-4422(06)70373-8

[12] Zigmond, A.S. and Snaith, R.P. (1983) The Hospital Anxiety and Depression Scale. Acta Psychiatrica Scandinavica, 67, 361-370. http://dx.doi.org/10.1111/j.1600-0447.1983.tb09716.x

[13] Deleu, D., Hanssens, Y. and Northway, M.G. (2004) Subcutaneous Apomorphine : An Evidence-Based Review of Its Use in Parkinson's Disease. Drugs Aging, 21, 687-709. http://dx.doi.org/10.2165/00002512-200421110-00001

[14] Hagell, P. and Odin, P. (2001) Apomorphine in the Treatment of Parkinson's Disease. Journal of Neuroscience Nursing, 33, 7-8, 21-34.

[15] Morgante, L., Basile, G., Epifanio, A., Spina, E., Antonini, A., Stocchi, F., et al. (2004) Continuous Apomorphine Infusion (CAI) and Neuropsychiatric Disorders in Patients with Advanced Parkinson's Disease: A Follow-Up of Two Years. Archives of Gerontology and Geriatrics, 291-296.

[16] Worth, P.F. (2013) When the Going Gets Tough: How to Select Patients with Parkinson's 
Disease for Advanced Therapies. Practical Neurology, 13, 140-152.

http://dx.doi.org/10.1136/practneurol-2012-000463

[17] Martí, M.J. and Kulisevsky, J. (2012) [Candidate Patient for Treatment with Continuous Apomorphine Infusion]. Revue Neurologique, 55, S15-S19.

[18] Antonini, A. and Odin, P. (2009) Pros and Cons of Apomorphine and L-Dopa Continuous Infusion in Advanced Parkinson's Disease. Parkinsonism \& Related Disorders, 15, S97S100. http://dx.doi.org/10.1016/s1353-8020(09)70844-2

[19] Clarke, C.E., Worth, P., Grosset, D. and Stewart, D. (2009) Systematic Review of Apomorphine Infusion, Levodopa Infusion and Deep Brain Stimulation in Advanced Parkinson's Disease. Parkinsonism \& Related Disorders, 15, 728-741. http://dx.doi.org/10.1016/j.parkreldis.2009.09.005

[20] Antonini, A. and Tolosa, E. (2009) Apomorphine and Levodopa Infusion Therapies for Advanced Parkinson's Disease: Selection Criteria and Patient Management. Expert Review of Neurotherapeutics, 9, 859-867. http://dx.doi.org/10.1586/ern.09.48

[21] Kulisevsky, J., Luquin, M.R., Arbelo, J.M., Burguera, J.A., Carrillo, F., Castro, A., et al. (2013) Advanced Parkinson's Disease: Clinical Characteristics and Treatment. Parte II. Neurologia, 28, 558-583. http://dx.doi.org/10.1016/j.nrl.2013.05.002

[22] Grandas, F. (2013) Subcutaneous Infusions of Apomorphine: A Reappraisal of Its Therapeutic Efficacy in Advanced Parkinson's Disease. Expert Review of Neurotherapeutics, 13, 1343-1353. http://dx.doi.org/10.1586/14737175.2013.839235

[23] Antonini, A., Isaias, I.U., Rodolfi, G., Landi, A., Natuzzi, F., Siri, C., et al. (2011) A 5-Year Prospective Assessment of Advanced Parkinson Disease Patients Treated with Subcutaneous Apomorphine Infusion or Deep Brain Stimulation. Journal of Neurology, 258, 579-585. http://dx.doi.org/10.1007/s00415-010-5793-z

[24] Grandas, F.J. and Sesar-Ignacio, A. (2012) [Subcutaneous Continuous Apomorphine Infusion: Treatment Initiation and Follow up]. Revue Neurologique, 55, S21-S24.

[25] O’Sullivan, S., Beddow, S., Lambert, P., Montgomery, G., Singh, J., Mills, J., et al. (2009) P2.088 Patient and Carer Opinions of Apomorphine Use in Parkinson's Disease. Parkinsonism \& Related Disorders, 15, S112. http://dx.doi.org/10.1016/S1353-8020(09)70439-0

[26] Frankel, J.P., Lees, A.J., Kempster, P.A. and Stern, G.M. (1990) Subcutaneous Apomorphine in the Treatment of Parkinson's Disease. Journal of Neurology, Neurosurgery, and Psychiatry, 53, 96-101. http://dx.doi.org/10.1136/jnnp.53.2.96

[27] Rambour, M., Moreau, C., Salleron, J., Devos, D., Kreisler, A., Mutez, E., et al. (2014) [Continuous Subcutaneous Infusion of Apomorphine in Parkinson's Disease: Retrospective Analysis of a Series of 81 Patients]. Revue Neurologique, 170, 205-215. http://dx.doi.org/10.1016/j.neurol.2013.10.012

[28] Bhidayasiri, R., Chaudhuri, K.R., LeWitt, P., Martin, A., Boonpang, K. and van Laar, T. (2015) Effective Delivery of Apomorphine in the Management of Parkinson Disease: Practical Considerations for Clinicians and Parkinson Nurses. Clinical Neuropharmacology, 38, 89-103. http://dx.doi.org/10.1097/wnf.0000000000000082 
Submit or recommend next manuscript to SCIRP and we will provide best service for you:

Accepting pre-submission inquiries through Email, Facebook, LinkedIn, Twitter, etc. A wide selection of journals (inclusive of 9 subjects, more than 200 journals)

Providing 24-hour high-quality service

User-friendly online submission system

Fair and swift peer-review system

Efficient typesetting and proofreading procedure

Display of the result of downloads and visits, as well as the number of cited articles

Maximum dissemination of your research work

Submit your manuscript at: http://papersubmission.scirp.org/ 